\title{
Zur Bestimmung von Halogen in organischen Substanzen. Von
}

\section{Hugo Schiff.}

Vor 28 Jahren habe ich in den Annalen der Chemie, Band 195, Seite $293^{1}$ ) zu diesem Zwecke eine Modifikation eines ursprünglich von Piria herrührenden Verfahrens beschrieben, wonach die organische Substanz in einem in einen grösseren Platintiegel umgekehrt eingesetzten kleineren Tiegel durch Erhitzen mit Alkali zersetzt wird. Wie ich aus einem Referat im Chemischen Zentralblatt, Jahrgang 1905, Band II, Seite 1381 ersehe, ist die Methode nicht so allgemein bekannt, als sie es ihrer Genauigkeit und Einfachheit der Ausführung nach zu sein verdient. Ich erlaube mir deshalb nochmals kurz auf dieselbe zurückzukommen, zumal die von S. Sadtler (a. a. O.) jetzt vorgeschlagene Ausführungsweise, nach meinen langjährigen Erfahrungen, zu kompliziert erscheint. Es bedarf weder eines besonders geformten noch eines mit Ansätzen versehenen Tiegels; wohl aber wende ich seit vielen Jahren weit kleinere Tiegel an, als ich 1878 angegeben habe. Der grössere Tiegel ist $36 \mathrm{~mm}$ hoch und oben $30 \mathrm{~mm}$ weit, der kleinere bei $23 \mathrm{~mm}$ Höhe oben $19 \mathrm{~mm}$ weit. Als Zersetzungsmasse dient in allen Fällen nur noch entwässertes, reines Natriumkarbonat, ohne Zusatz von Fig. 25. Kalk, da bei mälsiger Erhitzung die früher befürchtete Bildung von Cyanalkali ausgeschlossen ist. Wird nach dem Einsatz des kleineren Tiegels (siehe Figur 25) der ringförmige Raum mit Karbonat gefüllt, bis ersterer damit überdéckt ist, dann verbraucht man etwa $12 \mathrm{~g}$. Je nach der in der Substanz enthaltenen Menge Halogen wendet man 0,050 bis $0,200 \mathrm{~g}$ zur Analyse an.

Man erhitzt bei aufgelegtem Deckel mit ganz kleiner Flamme, so dass der untere Anteil des Karbonats eben schwach zu glühen anfängt,

1) Vergl. auch diese Zeitschrift 18, 480 . 
572 Schiff: Zur Bestimmung von Halogen in organischen Substanzen.

wenn in der Mitte die Substanz sich zu zersetzen beginnt. Bei allmählich grösserer Flamme erhitzt man in 20 bis 30 Minuten bis zu schwachem Glühen und Sintern der Masse, nicht bis zum Schmelzen. Das rasch abgekühlte Tiegelpaar wird in ein geräumiges Becherglas gebracht, dessen Boden etwa $1 \frac{1}{2} \mathrm{~cm}$ hoch mit Wasser bedeckt ist (Figur 26). Das Becherglas ist mit einem Uhrglas bedeckt, das in der Mitte durchbohrt, besser in eine Spitze ausgezogen ist, durch welche man Salpetersäure zutropfen lässt, so dass die Lösung in geschlossenem Raum erfolgt und etwaiges Verspritzen vermieden wird.

Fig. 26.

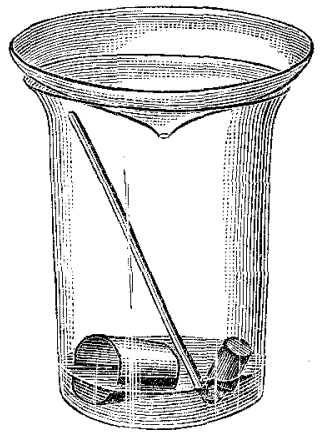

Nach Zusatz eines nicht zu grossen Überschusses von ${ }^{n} / 10^{-}$Silberlösung werden Lösung und Waschwasser durch ein trockenes, chlorfreies Filter in ein Messkölbchen bis zu $200 \mathrm{cc}$ filtriert. Zur Handhabung der Tiegel dient ein hackenförmig gebogener Glasstab. Nachdem die Lösung in üblicher Weise gut durchgemischt ist, dienen je $50 \mathrm{cc}$, um den Silberüberschuss durch Rhodan nach Volhard zurück zu titrieren. Bei Jodbestimmungen muss die Silberlösung zugesetzt werden, ehe man die Salpetersäure zutropfen lässt. Sehr flüchtige Verbindungen oder solche, welche bei der Zersetzung schwer zersetzbare, leicht flüchtige Halogenverbindungen entstehen lassen, können selbstverständlich nach dieser Methode nicht analysiert werden. Beleganalysen, sowie Angaben über Analyse füssiger Verbindungen, findet man in der anfangs zitierten älteren Mitteilung.

Florenz, Januar 1906. 